\title{
Adenosine Triphosphate-dependent Copper Transport in Isolated Rat Liver Plasma Membranes
}

Marjan Dijkstra, Gerda In 't Veld, Gerrit J. van den Berg, ${ }^{\ddagger}$ Michael Müller, ${ }^{*}$ Folkert Kuipers, and Roel J. Vonk Groningen Institute for Drug Studies, Departments of Pediatrics and *Internal Medicine, Division of Gastroenterology and Hepatology, University of Groningen, 9713EZ Groningen; and ${ }^{\ddagger}$ Interfaculty Reactor Institute, Delft University of Technology, 2629JB Delft,

The Netherlands

\begin{abstract}
The process of hepatobiliary copper $(\mathrm{Cu})$ secretion is still poorly understood: Cu secretion as a complex with glutathione and transport via a lysosomal pathway have been proposed. The recent cloning and sequencing of the gene for Wilson disease indicates that $\mathrm{Cu}$ transport in liver cells may be mediated by a Cu transporting P-type ATPase. Biochemical evidence for ATP-dependent $\mathrm{Cu}$ transport in mammalian systems, however, has not been reported so far. We have investigated $\mathrm{Cu}$ transport in rat liver plasma membrane vesicles enriched in canalicular or basolateral membranes in the presence and absence of ATP (4 mM) and an ATP-regenerating system. The presence of ATP clearly stimulated uptake of radiolabeled $\mathrm{Cu}\left({ }^{64} \mathrm{Cu}, 10 \mu \mathrm{M}\right)$ into canalicular plasma membrane vesicles and, to a lesser extent, also into basolateral plasma membrane vesicles. ATPdependent $\mathrm{Cu}$ transport was dose-dependently inhibited by the P-type ATPase inhibitor vanadate, and showed saturation kinetics with an estimated $K_{m}$ of $8.6 \mu \mathrm{M}$ and a $V_{\max }$ of $6.9 \mathrm{nmol} / \mathrm{min} / \mathrm{mg}$ protein. ATP-stimulated $\mathrm{Cu}$ uptake was similar in canalicular membrane vesicles of normal Wistar rats and those of mutant GY rats, expressing a congenital defect in the activity of the ATP-dependent canalicular glutathione-conjugate transporter (cMOAT). These studies demonstrate the presence of an ATP-dependent $\mathrm{Cu}$ transporting system in isolated plasma membrane fractions of rat liver distinct from cMOAT. (J. Clin. Invest. 1995. 95:412-416.) Key words: copper - bile secretion - P-type ATPase • vesicle transport • Wilson disease
\end{abstract}

Address correspondence to Marjan Dijkstra, MSc, University Hospital Groningen, Research Laboratory CMC IV, Oostersingel 59, 9713 EZ Groningen, The Netherlands. Phone: 50 - 6131 06; FAX: 50 - 6968 00 .

Received for publication 11 July 1994 and in revised form 23 September 1994.

1. Abbreviations used in this paper: blLPM, basolateral liver plasma membrane; cLPM, canalicular liver plasma membrane; cMOAT, canalicular multi-organic anion transporter (Glutathione-conjugate transporter); $\mathrm{Cu}$, copper; GY, Groningen Yellow.

J. Clin. Invest.

(C) The American Society for Clinical Investigation, Inc.

0021-9738/95/01/0412/05 \$2.00

Volume 95, January 1995, 412-416

\section{Introduction}

The mechanism(s) involved in hepatobiliary transport of copper $(\mathrm{Cu}),{ }^{1}$ essential for the maintenance of $\mathrm{Cu}$ homeostasis, are still unclear. It has been postulated that $\mathrm{Cu}$ is secreted into bile as a complex with glutathione $(\mathrm{GSH})(1,2)$. Alternatively, data from clinical (for review see reference 3 ) as well as experimental (4) studies have been interpreted to suggest that biliary secretion of $\mathrm{Cu}$ occurs by lysosomal exocytosis. We have recently provided evidence that $\mathrm{Cu}$ can be transported into bile by at least two different pathways in rats. First, a GSH-dependent route appears to be active in the removal of $\mathrm{Cu}$ after i.v. injection of the metal $(5,6)$. Second, a physiologically more important pathway independent of GSH is responsible for removal of "endogenous" or dietary copper (5). For this latter pathway a maximal secretion rate of $30-35 \mathrm{nmol} / \mathrm{h}$ per $100 \mathrm{~g}$ body weight was found under different experimental conditions with widely varying hepatic $\mathrm{Cu}$ concentrations (7). We have interpreted these results as indicative for the existence of a saturable $\mathrm{Cu}$-transporting system in rat liver (7). The recent identification of the gene responsible for Wilson disease, an autosomal recessive disorder of hepatobiliary $\mathrm{Cu}$ transport (8), encoding for a P-type ATPase appears to be in line with this option (9-11). However, so far no functional evidence for ATP-dependent $\mathrm{Cu}$ transport has been provided and the biochemical properties of this putative $\mathrm{Cu}$-transporting system remain to be established.

In the present study, plasma membrane vesicles from rat liver were shown to take up $\mathrm{Cu}$ in an ATP-dependent manner by a transport system sensitive to vanadate, a well-established inhibitor of P-type ATPases (12). The ATP-dependent $\mathrm{Cu}$ transporting system is distinct from the glutathione-conjugate transport system (cMOAT), which is defective in mutant Groningen Yellow (GY) rats (13). The hepatic expression of the Wilson disease gene encoding for a P-type ATPase (9), together with the presently demonstrated ATP-dependent $\mathrm{Cu}$ transport in rat plasma membrane preparations, strongly suggest the presence of a Cu-ATPase in the liver involved in (hepatobiliary) transport of $\mathrm{Cu}$.

\section{Methods}

Materials. Radiolabeled copper $\left({ }^{64} \mathrm{Cu}\right)$ was prepared by neutron bombardment in the reactor of the Interfaculty Reactor Institute of the Delft University of Technology (The Netherlands). The specific activity at the start of the experiments was about $4 \mathrm{MBq} / \mathrm{mmol} \mathrm{Cu}$. Adenosine triphosphate (ATP) and adenosine 5'-monophosphate (AMP), reduced 
glutathione (GSH), and sodium orthovanadate were purchased from Sigma Chemical Co. (St Louis, MO). Creatine phosphate and creatine kinase were obtained from Boehringer Mannheim (Mannheim, Germany). All reagents and solvents used were of analytical grade.

Animals and membrane preparations. Liver plasma membranes enriched in canalicular or basolateral fractions were prepared from normal male Wistar rats and mutant GY Wistar rats $(200-250 \mathrm{~g})$. Characteristics of GY rats are described in detail elsewhere (13). Animals were maintained on standard lab chow (RMH-B; Hope Farms N.V. Woerden, The Netherlands) and had free access to food and water. Fed animals were killed by decapitation between 9 and 10 a.m. and livers were harvested. Liver membrane fractions enriched in canalicular and basolateral domains, respectively, were prepared and characterized as described by Wolters et al. (14). The degree of contamination of canalicular and basolateral membrane fractions vice versa and their contamination with intracellular organelles was routinely estimated by the measurement of marker enzyme activities. Enrichments (ratio of specific activities in membranes to specific activities in the homogenate) of the intracellular marker enzymes glucose-6-phosphatase (endoplasmatic reticulum), succinate cytochrome-c reductase (mitochondria) and acid phosphatase (lysosomes) were $0.49,0.05$, and 3.7 in canalicular plasma membrane (cLPM) preparations and $0.24,1.52$, and 0.9 in basolateral plasma membrane (blLPM) preparations, respectively.

Analytical procedure. Marker enzymes for intracellular organelles, CLPM and blLPM were measured as described in reference 15 and references therein. Protein concentration was determined by the method of Lowry et al. (16) in the presence of $0.5 \%$ (wt/vol) sodium dodecylsulfate. Bovine serum albumine was used as a standard.

Transport assays. Transport of ${ }^{64} \mathrm{Cu}$ into the vesicles was measured using a rapid filtration technique. Experiments were performed at $37^{\circ} \mathrm{C}$ in a final volume of $1,000 \mu \mathrm{l}$. Unless specified otherwise, the incubation medium contained $10 \mathrm{mM}$ Tris/HCl, $\mathrm{pH} \mathrm{7.4,10 \textrm {mM } \mathrm { MgCl }}{ }_{2}, 0.25 \mathrm{M}$ sucrose, $4 \mathrm{mM}$ ATP, an ATP regenerating system $(10 \mathrm{mM}$ creatine phosphate and $100 \mu \mathrm{g} / \mathrm{ml}$ creatine kinase) and $5 \mathrm{mM} \mathrm{GSH}$. GSH was added to the incubation medium to prevent binding of $\mathrm{Cu}$ to membranebound glutathione S-transferases and other aspecific binding sites (17). Oxidation of GSH was prevented by extensive gassing of the solutions with nitrogen. Vials containing $1,000 \mu \mathrm{l}$ incubation medium under anaerobic conditions were stored at $-20^{\circ} \mathrm{C}$ and thawed immediately before the experiments. Radiolabeled $\mathrm{Cu}$ in the form of $\mathrm{Cu}$-acetate was added to the incubation medium at a final concentration of $10 \mu \mathrm{M}$. A preincubation time of $10 \mathrm{~min}$ was used to allow the formation of a $\mathrm{Cu}-\mathrm{GSH}$ complex. The uptake experiments were started by adding the membrane vesicles (final concentration $100 \mu \mathrm{g}$ protein) to the incubation medium. At appropriate times, aliquots of $100 \mu \mathrm{l}$ were taken and added to $2 \mathrm{ml}$ ice-cold buffer containing $10 \mathrm{mM}$ Tris/ $\mathrm{HCl}, \mathrm{pH} 7.4,10 \mathrm{mM} \mathrm{MgCl}$, $0.25 \mathrm{M}$ sucrose, and $10 \mathrm{mM}$ EDTA. Subsequently, vesicles were filtered through $0.45-\mu \mathrm{m}$ nitrocellulose filters (Sartorius AG, Goettingen, Germany) presoaked with $2 \mathrm{ml} 500 \mu \mathrm{M} \mathrm{CuCl}_{2}$ in saline and washed with $2 \mathrm{ml}$ ice-cold buffer. Vesicle-associated radioactivity retained on the filters was measured in a Packard $5000 \gamma$-counter. In control experiments ATP was replaced by AMP. All experiments were performed in triplicate. Sodium orthovanadate, an inhibitor of P-type ATPases, was added to the assay in concentrations of 50,100 and $200 \mu \mathrm{M}$. For estimates of $K_{\mathrm{m}}$ and $V_{\max }$, vesicles were incubated in triplicate with increasing amounts of ${ }^{64} \mathrm{Cu}$ ( 2 to $\left.100 \mu \mathrm{M}\right) . K_{\mathrm{m}}$ and $V_{\max }$ values were calculated by standard methods. In control experiments, ATP-dependent transport of $\left[{ }^{3} \mathrm{H}\right]$ taurocholate in CLPM and blLPM was determined as described elsewhere (18).

\section{Results and Discussion}

The recent cloning and sequencing of the genes for Menkes disease (19-21) as well as for Wilson disease (9-11) and the reported expression of these genes in affected organs, i.e., the liver for the Wilson disease gene, have provided an important
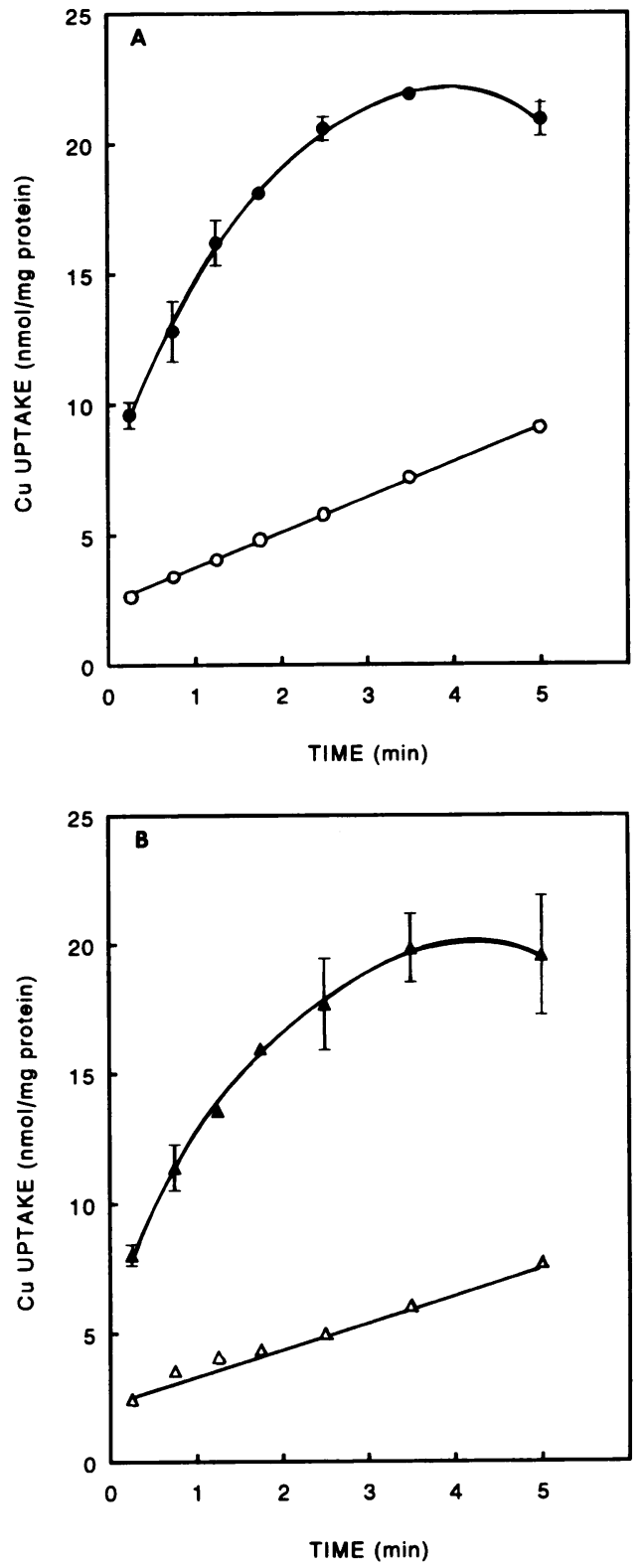

Figure 1. Cu uptake into rat liver cLPM vesicles prepared from normal Wistar rats $(A ;$ circles $)$ and from mutant GY rats $(B$; triangles $)$. Membrane vesicles ( $100 \mu \mathrm{g}$ of protein) were incubated at $37^{\circ} \mathrm{C}$ in medium containing $10 \mu \mathrm{M}{ }^{64} \mathrm{Cu}$ in the presence of an ATP-regenerating system (creatine phosphate and creatine kinase) and $4 \mathrm{mM}$ ATP (closed symbols) or $4 \mathrm{mM}$ AMP (open symbols). Uptake of ${ }^{64} \mathrm{Cu}$ was determined at indicated time points by rapid filtration technique, as detailed in Method. Results of experiments with three different preparations are shown as mean $\pm \mathrm{SD}$.

step forward in our understanding of the etiology of these inherited disorders of $\mathrm{Cu}$ transport. Menkes disease is a X-linked recessive disorder of $\mathrm{Cu}$ metabolism in which intestinal $\mathrm{Cu}$ absorption is disturbed (8). Wilson disease is an autosomal recessive disorder characterized by an inability to secrete $\mathrm{Cu}$ into bile, resulting in hepatic accumulation of $\mathrm{Cu}$ and eventually to progressive liver damage (8). Both genes apparently encode for a cation-transporting P-type ATPase and are highly homolo- 


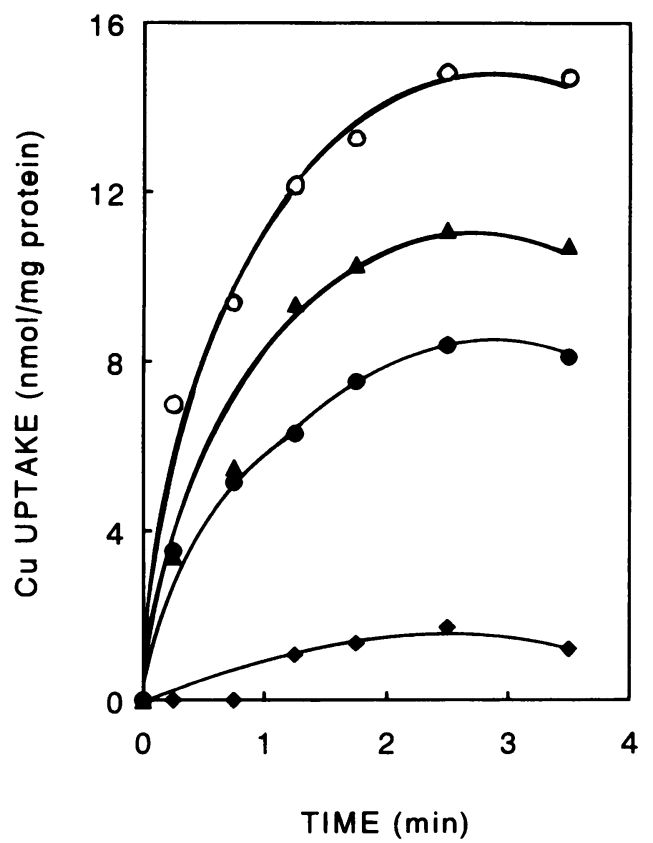

Figure 2. Effect of different concentrations $(50,100,200 \mu \mathrm{M})$ of sodium orthovanadate on ${ }^{64} \mathrm{Cu}$ uptake. Transport assays were performed with cLPM vesicles of normal Wistar rats in the presence of AMP and ATP. Presented data represent ATP-dependent Cu uptake, corrected for aspecific binding as measured in the presence of AMP. (O) No inhibitor; (४) $50 \mu \mathrm{M} ;(\bullet) 100 \mu \mathrm{M} ;(\bullet) 200 \mu \mathrm{M}$.

gous $(9,11)$. In addition, the reported sequences show close homology to those of a variety of bacterial P-type ATPases implicated in heavy metal efflux (22). In contrast to the Menkes disease gene, which shows expression in all body cells except the liver, the Wilson disease gene is predominantly expressed in liver, kidney and placenta. Until now, however, no biochemical evidence for ATP-dependent $\mathrm{Cu}$ transport in mammalian systems has been reported.

In this study we provide biochemical evidence for the presence of an ATP-dependent transport system for $\mathrm{Cu}$ in isolated rat liver plasma membranes. In the presence of ATP ( $4 \mathrm{mM}$ ) and an ATP regenerating system, a clear ATP-dependent uptake of radiolabeled $\mathrm{Cu}(10 \mu \mathrm{M})$ was measured in cLPM of normal Wistar rats (Fig. $1 A$ ). Initial $\mathrm{Cu}$ uptake rate in cLPM was 34 times higher than in control incubations containing AMP, indicating that an active ATP-dependent transport system is operating in these membrane preparations. This is in line with the interpretation of recent results from our laboratory, as suggesting the presence of a saturable transport system involved in hepatobiliary secretion of $\mathrm{Cu}$ in rats (7). To verify that ATPdependent $\mathrm{Cu}$ uptake rather than binding was measured, studies were performed after $5 \mathrm{~min}$ incubation of the vesicles, with increasing concentrations of sucrose $(0.25-1 \mathrm{M})$, which results in a decrease in the intravesicular volume. The amount of $\mathrm{Cu}$ taken up by vesicles decreased with increasing osmolarity of the extravesicular medium, indicating that $\mathrm{Cu}$ is transported into an osmotically active vesicular space. Extrapolation to an infinetely high medium osmolarity, i.e., a negligible intravesicular volume, revealed that $\sim 30 \%$ of the $\mathrm{Cu}$ associated with the vesicles could be attributed to membrane binding. The presence of EDTA in the stop buffer did not affect this aspecific binding.

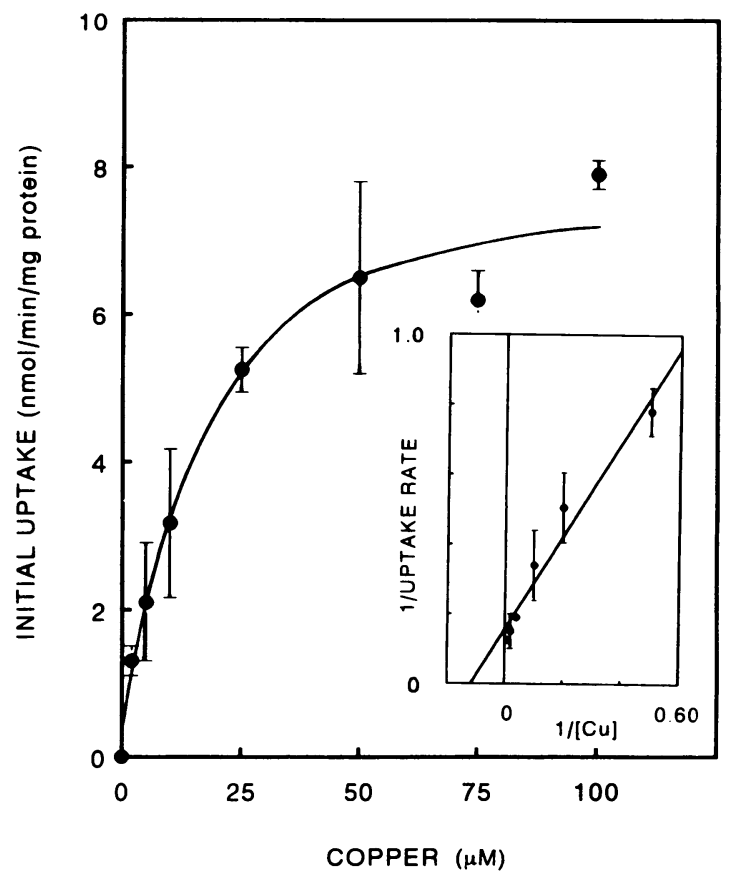

Figure 3. Kinetics of $\mathrm{Cu}$ transport in cLPM, showing the effect of $\mathrm{Cu}$ concentration on ATP-dependent $\mathrm{Cu}$ transport in cLPM of normal Wistar rats. Initial rapid uptake was determined at different $\mathrm{Cu}$ concentrations in the presence of $4 \mathrm{mM}$ ATP or $4 \mathrm{mM}$ AMP. Presented data represent ATP-dependent $\mathrm{Cu}$ uptake corrected for binding in the presence of AMP. Values are mean \pm SD of experiments performed in triplicate.

Vanadate, an inhibitor of P-type ATPases (12), inhibited $\mathrm{Cu}$ transport in a concentration-dependent fashion, as shown in Fig. 2 , indicating involvement of a P-type ATPase in this transport process. This is in accordance with the genetically obtained evidence for Menkes and Wilson disease (9-11, 19-21). This vanadate effect suggests that $\gamma$-phosphate transfer from ATP to the carrier is involved in the process of $\mathrm{Cu}$ transport.

ATP-dependent $\mathrm{Cu}$ uptake showed saturation kinetics with an apparent $K_{\mathrm{m}}$ value of $8.6 \mu \mathrm{M}$ and a $V_{\max }$ of $6.9 \mathrm{nmol} / \mathrm{min}$ per mg protein (Fig. 3). For comparison: the total liver $\mathrm{Cu}$ concentration under standard dietary conditions is about $40 \mu \mathrm{M}$, but the majority of hepatic $\mathrm{Cu}$ is bound to proteins (see below). Reported $K_{\mathrm{m}}$ values obtained from in vitro $\mathrm{Cu}$ uptake studies in brain hypothalamic slices (23) and in hepatocytes (24) as well as from efflux studies in hepatocytes (25) are in the same order of magnitude, i.e., 6,11 , and $5.5 \mu \mathrm{M}$, respectively.

Probably because of its toxic character, most of the intracellular $\mathrm{Cu}$ is complexed, i.e., bound to metallothionein, GSH, amino acids, or proteins. In our uptake studies, we have used an excess of GSH ( $5 \mathrm{mM})$ in the incubation medium for the following reasons: $(a)$ to abolish the toxic action of $\mathrm{Cu} ;(b)$ to saturate glutathione $\mathrm{S}$-transferases located at the canalicular membrane, thereby preventing binding of $\mathrm{Cu}$ to this enzyme; and $(c)$ because the physiological concentration of GSH in rat liver is $\sim 4-6 \mathrm{mM}$. Alexander et al. (2) and Ballatori et al. (1) have claimed that canalicular GSH-transporting system(s) may be involved in biliary secretion of several metals, including copper. In this view, transport of the metal is coupled to that of GSH. At the canalicular pole of liver cells transport systems 
Table I. Initial ATP-dependent Uptake Rate of Copper and Taurocholate

\begin{tabular}{lrcc}
\hline & cLPM & bLPM & cLPM/bLPM \\
\hline Copper & 5.2 & 4.1 & 1.3 \\
Taurocholate & 18.2 & 7.1 & 2.6 \\
\hline
\end{tabular}

Initial rates of ATP-dependent $\mathrm{Cu}$ transport (nmol/min per $\mathrm{mg}$ protein) and taurocholate transport (pmol/min per $\mathrm{mg}$ protein) in canalicular (cLPM) and basolateral liver plasma membranes (blLPM) of rat liver and the ratios between CLPM and bLPM transport. Cu transport (10 $\mu \mathrm{M}$ ) was measured as described in Methods, ATP-dependent taurocholate transport $(1 \mu \mathrm{M})$ as described by Wolters et al. (28).

are present for efflux of GSH, which appears to be ATP independent (26) and of GSH conjugates (cMOAT) (for review see 27 and 28). cMOAT is an established ATP-dependent transporter. However, from our earlier in vivo experiments (5) as well as from the present study, it appears that neither the GSH- nor the ATP-dependent GSH-conjugate transporting systems are involved in the process of biliary $\mathrm{Cu}$ secretion. A clear ATP. dependency of $\mathrm{Cu}$ transport was observed in the present studies, indicating that the ATP-independent GSH transporter is not involved in hepatobiliary Cu transfer. In addition, cLPM vesicles prepared from mutant GY rats, deficient in the hepatobiliary secretion of GSH-conjugates (cMOAT), showed ATP-stimulated $\mathrm{Cu}$ transport similar to control vesicles (Fig. 1, $A$ and $B$ ). Therefore, it is unlikely that cMOAT is involved in this process.

In both canalicular and basolateral membrane preparations ATP-dependent $\mathrm{Cu}$ transport activity was found. The initial $\mathrm{Cu}$ transport rate was $\sim 20 \%$ lower in blLPM than in CLPM $(5.2$ vs. $4.1 \mathrm{nmol} / \mathrm{min}$ per $\mathrm{mg}$ protein). This uptake in blLPM preparations can theoretically be due to contamination of the blLPM preparations with cLPM or $\mathrm{Cu}$-ATPase containing subcellular organelles or to the existence of two different ATPases, located on either side of the liver cell. The activity of leucine aminopeptidase (LAP), a commonly used marker enzyme for the canalicular membrane domain of the rat hepatocyte (14), was 41.2 $\mu \mathrm{mol} / \mathrm{h}$ per mg protein in cLPM compared with $3.9 \mu \mathrm{mol} / \mathrm{h}$ per $\mathrm{mg}$ protein for blLPM, indicating that our blLPM preparations were contaminated for at least $10 \%$ with canalicular membranes. On the other hand, the ratio between the initial uptake rate in CLPM and bILPM of ATP-dependent $\mathrm{Cu}$ transport was lower than the value for ATP-dependent taurocholate transport, as shown in Table I. Thus, contamination with CLPM is not likely to be the (only) cause of the observed $\mathrm{Cu}$ uptake in blLPM preparations. Another possible explanation for the appearance of transport activity in both preparations used is that liver plasma membrane preparations are always contaminated to some extent with subcellular organelles (14): the Cu-transport protein may also reside in a subcellular compartment, involved in hepatic disposition of $\mathrm{Cu}$. Concerning the molecular mechanism of hepatobiliary $\mathrm{Cu}$ transport a role of lysosomes has been suggested by several authors (see reference 3 and references therein; 4). Therefore, the localisation of Cu-ATPase activity in subcellular organelle preparations is currently being investigated in our laboratory, as are matters concerning regulation and specificity of the transport system(s). The demonstration of Cu-ATPase activity in human liver and its absence in Wilson disease liver is required for unequivocal proof for the role of Cu-ATPase in the etiology of Wilson disease. Techniques are operational in our laboratory for the isolation of CLPM and blLPM from human livers $(14,29)$. So far, we have provided strong indications that a saturable ATP-dependent $\mathrm{Cu}$ transport system is present in isolated rat liver membranes.

\section{Acknowledgments}

We thank Dr. H. Wolters for his advice. This work was partly supported by the "J. K. de Cock Stichting." G. I. 't. Veld is supported by grant 900-523-137 from the Netherlands Organization for the Advancement of Pure Scientific Research (NWO). F. Kuipers is an established investigator of the Netherlands Heart Foundation.

\section{References}

1. Ballatori, N., and T. W. Clarkson. 1985. Biliary secretion of glutathione and glutathione-metal complexes. Fundam. Appl. Toxicol. 5:816-831.

2. Alexander, J., and J. Aaseth. 1980. Biliary excretion of copper and zinc in the rat as influenced by diethylmaleate, selenite and diethyldithiocarbamate. Biochem. Pharmacol. 29:2129-2133.

3. Sternlieb, I. 1988. Copper and zinc. In The Liver Biology and Pathobiology. I. M. Arias, W. B. Jakoby, H. Popper, D. Schachter, and D. A. Shafritz, editors. 2nd edition. Raven Press, New York. 525-533.

4. Gross, J. B., B. M. Myers, L. J. Kost, S. M. Kuntz, and N. F. LaRusso. 1989. Biliary copper excretion by hepatocyte lysosomes in the rat. Major excretory pathway in experimental copper overload. J. Clin. Invest. 83:30-39.

5. Houwen, R., M. Dijkstra, F. Kuipers, E. P. Smit, R. Havinga, and R. J. Vonk. 1990. Two pathways for biliary copper excretion in the rat. The role of glutathione. Biochem. Pharmacol. 39:1039-1044.

6. Dijkstra, M., F. Kuipers, R. Havinga, E. P. Smit, and R. J. Vonk. 1990. Bile secretion of trace elements in rats with a congenital defect in hepatobiliary transport of glutathione. Pediatr. Res. 28:339-343.

7. Dijkstra, M., F. Kuipers, R. Havinga, and R. J. Vonk. 1994. Biliary copper secretion in rats. The role of lysosomes and glutathione. Hepatology. 19:581a (Abstr).

8. Danks, D. M. 1989. Disorders of copper transport. In The Metabolic Basis of Inherited Disease. C. R. Scriver, A. L. Beaudet, W. S. Sly, and D. Valle, editors. 6th ed. McGraw-Hill Inc., New York. 1411-1431.

9. Bull, P. C., G. R. Thomas, J. M. Rommens, J. R. Forbes, and D. W. Cox. 1993. The Wilson disease gene is a putative copper transporting P-type ATPase similar to the Menkes disease gene. Nature Genetics. 5:327-337.

10. Petrukhin, K., S. G. Fisher, M. Pirastu, R. E. Tanzi, I. Chernov, M. Devoto, L. M. Brzustowicz, E. Cayanis, E. Vitale, J. J. Russo, D. Matseone, B. Boukhgalter, W. Wasco, A. L. Figus, J. Loidianos, A. Cao, I. Sternlieb, O. Evgrafov, E. Parano, L. Pavone, D. Warburton, J. Ott, G. K. Penchaszadeh, I. H. Scheinberg, and T. C. Gilliam. 1993. Mapping, cloning and genetic characterization of the region containing the Wilson disease gene. Nature Genetics. 5:338343.

11. Tanzi, R. E., K. Petrukhin, I. Chernov, J. L. Pellequer, W. Wasco, B. Ross, D. M. Romano, E. Parano, L. Pavone, L. M. Brzustowicz, M. Devoto, et al. 1993. The Wilson disease gene is a copper transporting ATPase with homology to the Menkes disease gene. Nature Genetics. 5:344-350.

12. O'Neal, S. G., D. B. Rhoads, and E. Racker. 1979. Vanadate inhibition of sarcoplasmic reticulum $\mathrm{Ca}^{2+}$-ATPase and other ATPases. Biochem. Biophys. Res. Commun. 89:845-850.

13. Kuipers, F., M. Enserink, R. Havinga, A. B. M. van der Steen, M. J. Hardonk, J. Fevery, and R. J. Vonk. 1988. Separate transport systems for biliary secretion of sulfated and unsulfated bile acids in the rat. J. Clin. Invest. 81:15931599.

14. Wolters, H., M. Spiering, A. Gerding, M. J. H. Sloof, F. Kuipers, M. J. Hardonk, and R. J. Vonk. 1991. Isolation and characterization of canalicular and basolateral plasma membrane fractions from human liver. Biochim. Biophys. Acta. 1069:61-69.

15. Goldbarg, J. A., and A. M. Rutenberg. 1958. The colorimetric determination of leucine aminopeptidase in urine and serum of normal subjects and patients with cancer and other diseases. Cancer. 11:283-291.

16. Lowry, O. H., N. J. Rosenbrough, A. L. Farr, and R. J. Randall. 1951. Protein measurement with folin reagent. J. Biol. Chem. 193:265-275.

17. Dierickx, P. J. 1986. In vitro interaction of organic copper (II) compounds with soluble glutathione S-transferases from rat liver. Res. Commun. Chem. Pathol. Pharmacol. 51:285-288.

18. Müller, M., T. Ishikawa, U. Berger, C. Klunemann, L. Lucka, A. Schreyer, 
C. Kannich, W. Reutter, G. Kurz, and D. Keppler. 1991. ATP-dependent transport of taurocholate across the hepatocyte canalicular membrane mediated by a 110 kDa glycoprotein binding ATP and bile salt. J. Biol. Chem. 266:18920-18926.

19. Chelly, J., Z. Tümer, T. Tonnesen, A. Petterson, Y. Ishikawa-Brush, N. Tommerup, N. Horn, and A. P. Monaco. 1993. Isolation of a candidate gene for Menkes disease that encodes a potential heavy metal binding protein. Nature Genetics. 3:14-19.

20. Vulpe, C., B. Levinson, S. Whitney, S. Packman, and J. Gitschier. 1993. Isolation of a candidate gene for Menkes disease and evidence that it encodes a copper-transporting ATPase. Nature Genetics. 3:7-13.

21. Mercer, J. F. B., J. Livingston, B. Hall, J. A. Paynter, C. Begy, S. Chandrasekharappa, P. Lockhart, A. Grimes, M. Bhave, D. Siemieniak, and T. W. Glover 1993. Isolation of a partial candidate gene for Menkes disease by positional cloning. Nature Genetics. 3:20-25.

22. Fagan, M. J., and M. H. Saier, Jr. 1994. P-type ATPases of eukaryotes and bacteria: sequence analyses and construction of phylogenetic trees. J. Mol. Evol. 38:57-99.

23. Hartter, D. E., and A. Barnea. 1988. Brain tissue accumulates ${ }^{67} \mathrm{Cu}$ by two ligand-dependent saturable processes. A high affinity, low capacity and a low affinity, high capacity process. J. Biol. Chem. 263:799-805.

24. Schmitt, R. C., H. M. Darwish, J. C. Cheney, and M. J. Ettinger. 1983. Copper transport kinetics by isolated rat hepatocytes. Am. J. Physiol. 244:G183G191.

25. Darwish, H. M., R. C. Schmitt, J. C. Cheney, and M. J. Ettinger. 1984 Copper efflux kinetics from rat hepatocytes. Am. J. Physiol. 246:G48-G55.

26. Fernandez-Checa, J. C., H. Takikawa, T. Horie, M. Ookhtens, and N. Kaplowitz. 1992. Canalicular transport of reduced glutathione in normal and mutant Eisai hyperbilirubinemic rats. J. Biol. Chem. 267:1667-1673.

27. Arias, I. M., M. Che, Z. Gatmaitan, C. Leveille, T. Nishida, and M. St Pierre. 1993. The biology of the bile canaliculus. Hepatology. 17:318-329.

28. Zimniak, P., and Y. C. Awasthi. 1993. ATP-dependent transport systems for organic anions. Hepatology. 17:330-339.

29. Wolters, H., F. Kuipers, M. J. H. Slooff, and R. J. Vonk. 1992. Adenosine triphosphate-dependent taurocholate transport in human liver plasma membranes. J. Clin. Invest. 90:2321-2326. 